CASES OF ACCIDENTAL POISONING.

BY EDGAR BECKIT TRUMAN, M.D., F.C.S., PUBLIC ANALYST TO THE BOROUGH OF NOTTINGHAM AND TO THE COUNTY OF NOTTS.

\section{By Arsentc.}

ON Dec. 5th, 1882, I gave evidence at an inquest held by Mr. A. Browne, deputy district coroner for Notta, at Stapleford, near Nottingham. On Nov. 19th, 1882, C. Wobtained from a shop kept by Mrs. X- a paper packet of what was believed to be magnesium carbonate. It was dispensed by Mrs. X- out of a large bottle containing with the powder a leaden tablespoon as a measure. C. W and his wife each took a teaspoonful of the powder in milk, and shortly after suffered from vomiting and purging. The husband, after much pain and discomfort, recovered; but the wife died on the third day afterwards. A post-mortem was made, and the appearances of the viscera were those of death from an irritant poison. The case was referred to me, and on Nov. 25th I received four jars containing respectively the stomach, liver, duodenum, and rectum, a bottle with the contents of the stomach, a large wide-mouthed bottle half full of a white powder, and with a leaden spoon within, and a paper packet of a white powder. In the viscera and contents of the stomach I found arsenic. The white powder in the bottle gave off the usual reactions of arsenious acid and of magnesium carbonate. The relative quantities differed in different parts of the whole, four samples taken giving percentages of arsenious acid of 46,55 , 45 , and 55 , or an average of 50 per cent. A teaspoonful of the powder levelled up weighed twenty-one grains, so that in a teaspoonful there was about ten grains of arsenic. There was no other metal present. Lead from the spoon was blamed for the result at first. The powder in this paper was identical in character with that in the bottle. I seems that Mr. B- had kept a shop in this neighbourhood, and obtained his drugs from a leading druggist in Notting ham, who in turn got his stock from London. This Mr. B - had, however, given up his shop in July, 1881, and at that time sold Mrs. $X$ - several quantities of simple drugs, including a large bottle of magnesia. The bottle sold to Mrs. $X$ - was proved to be the same as that from which Mrs. $\mathrm{X}$ - dispensed the powder to $\mathrm{C}$. W-. It was a bottle known to the whole village in fact. Mr. B-_'s nephew gave this in evidence, and the nephew's wife said that she had given of its contents frequently to her own baby, and it had never suffered any ill effects. She said she was sure that the bottle when sold was not so full as when produced at the inquest. The bottle was not labeled. The coroner said, in the course of his remarks, that he was afraid it would remain a mystery as to how the arsenic got into the powder, for according to Mrs. X-'s evidence, the contents of the bottle were just the same as when she bought the powder from Mr. B-C. The jury returned a verdict that the deceased died from taking are enicaccidentally mixed with magnesia, but how such mixture took place there was no evidence to show.

\section{By STRYCHNIA.}

On March 18th, 1884, I gave evidence at an inquest held by Dr. Houslev, district coroner for Notts, at Warsop, near Mansfield. W.' H- had a daughter, the deceased, who was ten years old at the time of her death. She occasionally suffered from toothache. On January 4 th-i.e., six weeks before the death, finding her in pain from toothache, he sent her to a druggist's shop in Warsop for some Epsom salts. Of this he gave her a teaspoonful in some hot water. She then went to bed; her father and his wife, the child's stepmother, shortly afterwards retired. About 10 o'clock (time of child going to bed not given) the child began to scream. Her father went to her, and she said, "Father, father, I am dying." She complained of pains in the legs, which were stiff and extended. He carried her about the room for twenty minutes, and then put her on the bed. At intervals she screamed and asked not to be put on the ground. When sitting on the bed she said, "It's coming on again." She made "funny faces," and he thought she was "going off her head." After half an hour she vomited and seemed better, and he did not think it necessary to send for a doctor. $\mathrm{He}$ gave her a little whisky and water, and occasionally after this there was twitching in the arms, body, and legs. In an hour she went to sleep. Next morning she seemed dull and drowsy. He did not think at the time that the salts were the cause of her symptoms. On February 16th the child again complained of the toothache, and her father gave her half a teaspoonful of the same salts in hot water. She went to lie down, and in a quarter of an hour cried out for him. He found her suffering in the same way as before. He sent for Mr. Stein of Warsop, who found the girl unconscious and almost pulseless, with the face quite pale and the lips livid. She went into a series of convulsions, which attacked the body, arms, and legs. She shortly after died. Mr. Stein made a post-mortem, and finding no appearance of death from natural causes, and indeed stating that the symptoms were those of strychnine poisoning, reserved the stomach for analysis. On February 20 th $I$ received the following articles: (1) A white jar, covered and sealed ; (2) a powder in a blue paper ; (3) a small bottle labelled "toothache tincture."

1. The jar contained a small human stomach, tied at both ends, weighing $13 \frac{1}{2}$ oz., with the contents, which latter weighed $8 \frac{1}{4} \mathrm{oz}$. The mucous membrane was natural. The contents consisted of a brown thick fluid, with an acid reaction, and of some lumps of cooked flesh resembling ham and some fat and potato. I examined these contents for magnesium sulphate, finding both base and acid present. I then took half the stomach and half the contents, making an acid watery extract, which I exhausted with alcohol, the alcoholic extract dissolved in water being treated, by a well-known method, alternately with chloroform and ammonia and sulphuric acid. Finally I obtained from the half of the stomach and contents a pure white crystalline evaporate from alcoholic solution, weighing 007 of a grammei. e., in grains, for the whole stomach, $007 \times 2 \times 15=21$ grain. I tested this alkaloid in the usual way for strychnia. The solution in acetic acid was intensely bitter to the taste, gave a yellow precipitate with chromate of potassium, and the solid showed the violet reaction with manganese binoxide and sulphuric acid. Nitric acid did not redden the solid, showing absence of brucia. To show that this substance was altogether strychiia, and not a mixture with some other alkaloid, I made use of two methods, chemical and pbysiological. The colour, reaction, and bitterness to the taste I found most marked to 00001 of a gramme, and the physiological test I used as follows. Frogs I found it impossible to get, and instead thereof made use of toads, just then spawning and easily obtained. I took male toads of equal size, and made two solutions, one of the crystalline evaporate and one of a pure stri chnia from Morson's, of the same strength. Into toad A I injected by the hypodermic syringe $\cdot 005$ gramme of the alkaloid from the stomach; into toad B $\cdot 005$ gramme of pure strychnia. A had first marked tetanic spasm in eighteen minutes; $B$ in twenty minutes. $A$ died in six hours twenty-three minutes; $B$ in six hours thirty-thre minutes. A third toad I put unwounded into a vessel containing a grain of acetate of strychnia. He bad no symptoms for twenty-seven hours and a half, but died of tetanus in forty-six hours and a half, showing how much longer the thickly tuberculated skin of the toad resists the entrance of a solution of strychnia than in the case of the frog. The dose, 0001 grain, recommended to produce tetanus in the frog, by a solution in which it is placed unwounded, had not the least effect on the toad for seventy-two hours, when I removed it, and it showed no sign whatever of tetanus afterwards.

2. The blue paper packet contained a white crystalline powder, weighing 355 grains. This was what the father had given doses of to the child, and was supposed to be Epsom salts. There was no label, either of the substance or of the druggist's name. I analysed this substance for oxalic acid and for zinc, with a negative result. I obtained the usual evidence of magnesium and of sulphuric acid. I found and separated, by of course a much simpler proceeding than in No. 1, strychnia in the alkaloidal state, and amounting to 3 per cent. of the whole, but not uniformly distributed. A teaspoonful levelled up weighed $52 \frac{1}{2}$ grains ; so that it would contain about one and a balf grains of strychnia, and the half teaspoonful about three-fourths of a grain.

3 The "toothache tincture" contained no strychnia, and consisted of a solution of camphor in chloroform. It had been used by the child.

The stepmother deposed that her husband had three children, but none by her. On two occasions, by his desire, she bought strychnia for the purpose of poisoning rats (the father was a gamekeeper); but said that the 
last quantity, after what was necessary, was thrown into the fire; whilst the father said he distinctly remembered throwing it into a stream. After some little pressure, the stepmother admitted that the child's life was insured Two of the neighbours deposed that in January of this year each of them had bought Epsom salts at the druggist's where the deceased child had purchased some. In one case the witness gave her daughter, aged ten, as much as would lie on a shilling, and the girl suffered from aching and stiffness of the arms and legs and twitching. Witness threw away the remainder of her salts when she heard of the death of deceased. In the other case the witness had taken a teaspoonful of the salts herself, had twitchings of the arms and legs, but vomited and soon recovered. The druggist who sold the salts deposed that he had no strychnia in the solid state, and had never had it in stock. The bulk of Epsom salts from which he supplied deceased came from a wholesale druggist's in London. The coroner reviewed the evidence at some length, pointing out that the questions for the jury to consider were: Whether the deceased died from poisoning by strychnia; and, if so, how was it mixed with the salts? Was it mixed wilfully and intentionally? Were the salts contaminated by the father, the local, or the London, druggist? He thought that the wisest course would be to return an open verdict, leaving any future action to be taken by the police, if they obtained sufficient information. The jury's verdict was: "That deceased died from strychnia poisoning; but there was not sufficient evidence to show how the poison became mixed with the salts."

Remarks. - I have brought forward these two cases, not for their pathological or chemical aspects but on a medicolegal account. They are similar, inasmuch as it was impossible to trace how, when, and by whom the mixture of poison and medicine took place. It seems to me to offer a new and facile field for the poisoner of the future. If $A$ buys a medicine of $B$ and a poison of $C$, and mixes them, who is to say whether $A$ did so or whether $B$ did not sell the medicine adulterated with the poison? Of course the greater number of hands the substance bought passes through the greater the difficulty of finding out the person who mixed with it a poison. In the first ce se the powder which killed Mrs. W - was bought of Mrs. X who bought it of Mr. B - who bought it of a druggist in Nottingham, who would buy of some London house. In the second case the salts were bought of a local man who bought of a London house. It would have been better in the second case if the police had seized the bulk from which the salts were dispensed by the local druggist.

The cases also were similar in respect of the varying strength of samples taken from different parts of the whole; looking indeed as if the mixture were an accidental one. The verdict of the jury was in each case in almost identical words, to the effect that death was caused by the poisoned medicine, but that there was no evidence to show how the mixture had been effected. My own theory with regard to the first case is as follows. Mr. B- had been in the habit of keeping a little arsenic for the purpose of sheep-washing this fact he kept in the background as much as possible, and there was no arsenic or indeed any drug on his premises at the time of the inquest. He probably or possibly kept this arsenic in a paper without a label, and when the necessity for using it had passed by he would push it into a corner of a cupboard and forget all about it. When transferring some of his stock to Mrs. X-, he would turn out this white powder in a paper; not labeled, he would imagine it was an additional quantity of what it so much resembled-viz., the magnesium carbonate-and would put it into the bottle containing his stock of the same. When Mr. B-'s nephew's wife gave her baby some magnesia out of this bottle, it would be before the transfer to Mrs. X - took place. As to her saying that the bottle was fuller when produced at the inquest than when sold to Mrs. X - that was possibly due to her imagination. The second case presents much more difficulty. The husband and wife, when examined separately, differed as to the mode in which the residual strychnia was disposed of and it may perhaps be considered singular that the father, having poisoned rats so frequently, and most likely seen them in the convulsive stage, should have had no suspicion of the real state of things after the first dose. As to the whole teaspoonful being recovered from and the half proving fatal, in the first place the vomiting in the first instance would diminish the amount of poison absorbed, and, in the second place, too great reliance cannot be placed on loose measurements; the whole teaspoonful may have been a small one, and the half a large one. If the packet bought were really a two-ounce one, there must have been, after the teaspoonful and a half had been taken, an ounce unaccounted for; but as 355 grains (sent to me) $+50+25$ (a easpoonful and a half) $=430$, the packet may have been an ounce only. As to the depositions of the two neighbours that they had suffered from twitching after taking salts purchased from the same drug. gist, we may perhaps attribute this, in the absence of any but their own testimony, to vivid imaginations acting posteriorly to the fact of the girl's death. I was told that two samples of salts bought from the same druggist had been sent for analysis to a chemist, and with negative results but this was not put in evidence.

Nottingham.

\section{"PRICKLY HEAT."}

BY HENRY T. WHARTON, M.A. OXON., HONORARY SURGEON TO THE KILBURN DISPENSARY, ETC.

THIs distressing affection, so common among Europeans in tropical climates, is too rarely met with in England to figure in our text-books under anything but its mere name of "lichen tropicus." The apparent impossibility of relieving the fearful burning heat or the tormenting prickly itching seems to excuse dermatologists from even suggesting a remedy. Nevertheless the disease, although seldom recognised, is far from being unknown in this country. A well-marked case which has come under my observation, and which has ended in a complete cure, seems therefore worthy of being recorded.

My patient, a medical man, after passing the age of thirty suffered year by year continually increasing distress as each summer came round. $\mathrm{He}$ is a man of exceptionally good health, who knows nothing of indigestion, biliousness, or liver complaint in his own individual experience. Atlast his "prickly heat" became intolerable. Not only was the follicular lichenous inflammation so conspicuous on his back that he could not bear to take a Turkish bath in public; but the eruption would appear in considerable patches on his forearms, so that he was ashamed to turn up his shirt.sleeves in ever so troublesome an obstetric case. The disfigurement was almost as serious a matter as the pain. Yet, after having been out at night he would often return to his bed to suffer hours of the torture of his "prickles;" the least increase in the action of the skin brought them on; nor did any treatment prove adequate to bring the slightest relief From May to November he was a martyr to his troublesome malady. He consulted all his friends and more than one distinguished specialist. His efforts to get cured were as unremitting as they were unavailing; no known art could aid him.

At last it oceurred to me that perhaps the light shortsleeved India-gauze vests that he wore in the summer had some share in the causation of his agony; they were too thin either to absorb the perspiration or to protect the skin from sudden (but perniciously gratefal) chills. In fact, his endeavour to keep cool was the very cause of his suffering from the heat. I accordingly advised him to wear through. out the summer the thickest long-sleeved vests made entirely of wool, such as he wore in the depth of winter. The result was the absolute cessation of his experience of "prickly heat." All last summer, and up to the present date of this, he has never felt a symptom of the recurrence of his dreaded agony.

I may further mention, as it may throw some light upon the case, that for years my patient suffered a transient attack of urticaria-itching without any outward signz-after a cold bath. Since he has taken to the constant use of hot water for all his ablutions, this irritation has never returned. It would be interesting to learn whether Indian practitioners have ever essayed to combat the excruciating anguish of "prickly heat" by any method similar to mine.

St. George's-road, N.W.

GuY's Hospital UNIVERsities DinNeR. - A pleasant gathering of the members of the Universities of Oxford and Cambridge now at Guy's Hospital was held on Wednesday, July 16th, at the Holborn Restaurant, with Mr. J. N. C. Davies Colley, M.A., M. C., in the chair. It was decided that in order to bring the members of the Universities together the dinner should be held annually. 